\title{
Neurological complications during the course of severe COVID-19: is it just the tip of the iceberg?
}

\author{
Gulcin Koc Yamanyar, Burcin Halacli, Mehmet Yildirim, Arzu Topeli \\ Division of Intensive Care Medicine, Department of Internal Medicine, Hacettepe University Faculty of Medicine, Ankara, Turkey
}

\section{Dear Editor:}

During the coronavirus disease 2019 (COVID-19) pandemic, expanding data on the presence of neurological complications has increased the interest in neurological involvement of COVID-19 and its possible pathophysiological mechanisms. Recently, many studies have been published showing that COVID-19 may cause neurological disorders [1-3]. The incidence of neurological disorders has been reported higher in severe patients requiring intensive care admission [2]. In COVID-19 patients, timely recognition and intervention of neurological disorders is crucial to improve outcomes. For this reason, we aimed to share the characteristics of neurological diseases in critically-ill COVID-19 patients who were admitted to our COVID-intensive care unit (ICU) between March 21, 2020 and March 21, 2021 for 1-year period.

In our ICU, 16 (4.9\%) of 328 critically ill confirmed COVID-19 patients manifested with severe neurological diseases. Neurological findings were present in half of the patients at hospital admission and in the remaining eight patients, neurological problems were detected after ICU admission, in five of them after failure of awakening from cessation of sedation and in three of them after development of hemiparesis. Patients' characteristics are shown in Table 1. There were 13 cases (81.3\%) with ischemic stroke (IS), 10 of these patients had no previous history of IS. There was one case with Guillain-Barre syndrome, one with intracranial hemorrhage, and one with meningitis. IS was the most common neurological disease in our registry similar to other studies. However, when the risk factors of 13 patients regarding IS were evaluated, there was only one patient who did not have any risk factors for IS. Other patients had at least one risk factor for IS. There was hypertension in six patients, diabetes mellitus in five patients, cardiac disease in four patients, cerebrovascular disease in three patients and a long-term intensive care stay with renal failure and septic shock in one patient. Overall mortality was $37.5 \%$ in patients with neurological disease, whereas the 1-year mortality was $32.3 \%$ in our COVID-19 cohort.

The fact that detailed neurological evaluation could not be performed during a pandemic in the context of ICU, indicates that the incidence of neurological diseases might even be more than that reported, increasing morbidity and mortality. Patients can present with neurological complications before development of respiratory symptoms and signs during the COVID-19 course. Suspicion threshold for neurological complications should be low in cases of encephalopathy even if focal neurological deficits were not detected in COVID-19

\section{Letter to the Editor}

Received: October 5, 2021

Revised: November 29, 2021

Accepted: December 1, 2021

Corresponding author

Gulcin Koc Yamanyar

Division of Intensive Care Medicine, Department of Internal Medicine, Hacettepe University Faculty of Medicine, Hacettepe st., Ankara 06230, Turkey

Tel: +90-312-305-36-27

Fax: +90-312-305-23-81

E-mail:dr.gulcinkoc@hotmail.com

Copyright (C) 2022 The Korean Society of Critical Care Medicine

This is an Open Access article distributed under the terms of Creative Attributions Non-Commercial License (https:// creativecommons.org/li-censes/by-nc/4.0/) which permits unrestricted noncommercial use, distribution, and reproduction in any medium, provided the original work is properly cited. 

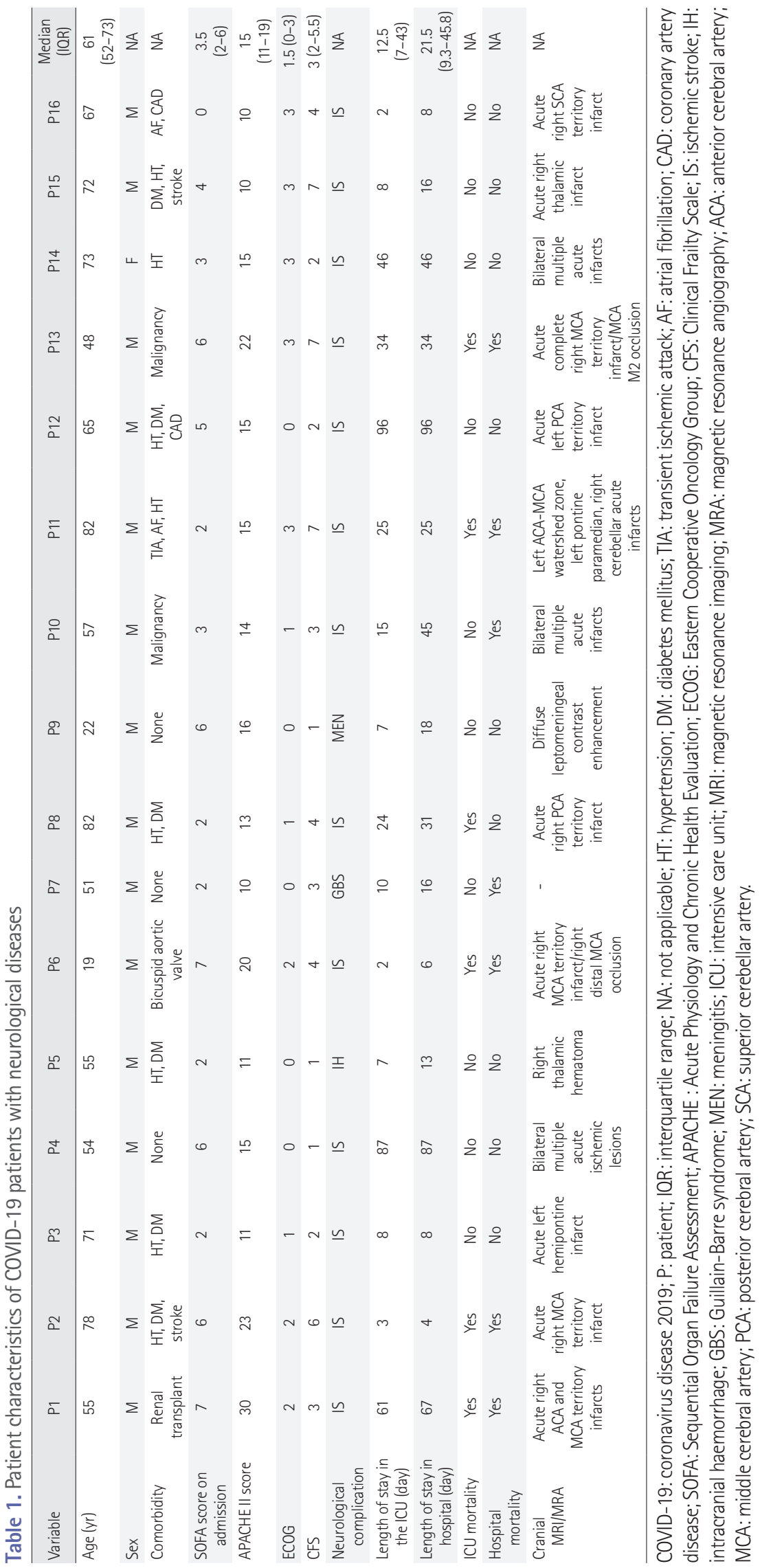
patients. Although many studies have been published to reveal the relationship between COVID-19 and stroke, the majority of patients with IS during COVID-19 have advanced age and co-morbidities similar to our patients $[4,5]$. In a study of a high-volume center examining the relationship between COVID-19 and stroke, usual causes of stroke were found in most of the stroke cases. Moreover, all patients with an acute stroke without a usual etiology presented a severe infection requiring mechanical ventilation [5]. We believe that detailed etiological evaluations will give more accurate results in terms of determining COVID-19 related neurological complications. Therefore, more studies are needed to define the real incidence of neurological complications of COVID-19 and to clarify the underlying mechanism and causality between COVID-19 and neurological diseases.

\section{CONFLICT OF INTEREST}

No potential conflict of interest relevant to this article was reported.

\section{ORCID}

Gulcin Koc Yamanyar https://orcid.org/0000-0002-4929-8181 Burcin Halacli https://orcid.org/0000-0002-7216-7438

Mehmet Yildirim https://orcid.org/0000-0002-0526-5943

Arzu Topeli

\section{AUTHOR CONTRIBUTIONS}

Conceptualization: GKY, BH, AT. Data curation: GKY, BH, MY. Methodology: BH, MY, AT. Project administration: GKY, BH, AT. Visualization: GKY. Writing-original draft: GKY, BH. Writing-review \& editing: GKY, BH, AT.

\section{REFERENCES}

1. Whittaker A, Anson M, Harky A. Neurological manifestations of COVID-19: a systematic review and current update. Acta Neurol Scand 2020;142:14-22.

2. Taquet M, Geddes JR, Husain M, Luciano S, Harrison PJ. 6-Month neurological and psychiatric outcomes in 236379 survivors of COVID-19: a retrospective cohort study using electronic health records. Lancet Psychiatry 2021;8:416-27.

3. Misra S, Kolappa K, Prasad M, Radhakrishnan D, Thakur KT, Solomon T, et al. Frequency of neurologic manifestations in COVID-19: a systematic review and meta-analysis. Neurology 2021;97:e2269-81.

4. Li Y, Li M, Wang M, Zhou Y, Chang J, Xian Y, et al. Acute cerebrovascular disease following COVID-19: a single center, retrospective, observational study. Stroke Vasc Neurol 2020;5:27984.

5. Requena M, Olivé-Gadea M, Muchada M, García-Tornel Á, Deck M, Juega J, et al. COVID-19 and stroke: incidence and etiological description in a high-volume center. J Stroke Cerebrovasc Dis 2020;29:105225. 